\title{
Enhanced bioavailability of sirolimus via preparation of solid dispersion nanoparticles using a supercritical antisolvent process
}

This article was published in the following Dove Press journal:

International Journal of Nanomedicine

23 November 2011

Number of times this article has been viewed

\author{
Min-Soo Kim' \\ Jeong-Soo Kim' \\ Hee Jun Park' \\ Won Kyung Chol,3 \\ Kwang-Ho Cha ${ }^{1,3}$ \\ Sung-Joo Hwang ${ }^{2,3}$ \\ 'College of Pharmacy, Chungnam \\ National University, Daejeon, Republic \\ of Korea, ${ }^{2}$ College of Pharmacy, \\ ${ }^{3}$ Yonsei Institute of Pharmaceutical \\ Sciences, Yonsei University, Incheon, \\ Republic of Korea
}

Background: The aim of this study was to improve the physicochemical properties and bioavailability of poorly water-soluble sirolimus via preparation of a solid dispersion of nanoparticles using a supercritical antisolvent (SAS) process.

Methods: First, excipients for enhancing the stability and solubility of sirolimus were screened. Second, using the SAS process, solid dispersions of sirolimus-polyvinylpyrrolidone (PVP) K30 nanoparticles were prepared with or without surfactants such as sodium lauryl sulfate (SLS), tocopheryl propylene glycol succinate, Sucroester 15, Gelucire 50/13, and Myrj 52. A mean particle size of approximately $250 \mathrm{~nm}$ was obtained for PVP K30-sirolimus nanoparticles. Solid state characterization, kinetic solubility, powder dissolution, stability, and pharmacokinetics were analyzed in rats.

Results: X-ray diffraction, differential scanning calorimetry, and high-pressure liquid chromatography indicated that sirolimus existed in an anhydrous amorphous form within a solid dispersion of nanoparticles and that no degradation occurred after SAS processing. The improved supersaturation and dissolution of sirolimus as a solid dispersion of nanoparticles appeared to be well correlated with enhanced bioavailability of oral sirolimus in rats. With oral administration of a solid dispersion of PVP K30-SLS-sirolimus nanoparticles, the peak concentration and $\mathrm{AUC}_{0 \rightarrow 12 \mathrm{~h}}$ of sirolimus were increased by approximately 18.3-fold and 15.2-fold, respectively.

Conclusion: The results of this study suggest that preparation of PVP K30-sirolimus-surfactant nanoparticles using the SAS process may be a promising approach for improving the bioavailability of sirolimus.

Keywords: sirolimus, solubility, bioavailability, supercritical antisolvent, nanoparticles

\section{Introduction}

Sirolimus, a triene macrolide antibiotic with immunosuppressive activity, was isolated from Streptomyces hygroscopicus in 1978. ${ }^{1,2}$ The formulation of an oral dosage form of sirolimus is challenging owing to its poor water solubility, which is $2.6 \mu \mathrm{g} / \mathrm{mL}$ at $25^{\circ} \mathrm{C} .{ }^{3}$ In addition, sirolimus is very unstable in phosphate-buffered saline and HEPES buffer under all conditions; their degradation effect on the drug is slower at $4^{\circ} \mathrm{C}-8^{\circ} \mathrm{C}$ and fastest at $37^{\circ} \mathrm{C}$, at which temperature almost all of the drug is destroyed within 24 hours. ${ }^{4}$ To improve the solubility of sirolimus, various oral formulations, such as inclusion complexes, ${ }^{5,6}$ liposomes, ${ }^{7}$ nanocrystals, ${ }^{8,9}$ and solid dispersions ${ }^{10}$ with polyethylene glycol (PEG), have been studied.

In the field of pharmaceutical technology, solid dispersions are commonly used for solving problems related to poor water solubility and poor bioavailability
Correspondence: Sung-Joo Hwang College of Pharmacy, Yonsei University, 162-I Songdo-dong, Yeonsu-gu, Incheon 406-840, Republic of Korea Tel +82327494518

Fax +82327494105

Email sjhI I@yonsei.ac.kr 
of active ingredients, as well as instability and dosing problems. ${ }^{11,12}$ The selection of a carrier and the method of preparation have important influences on the properties of the resulting solid dispersion. Solid dispersions can be prepared by fusion, solvent, and solvent-fusion methods. The most relevant technologies for the manufacture of solid dispersions are vacuum drying, spray drying, freeze drying, hot spin mixing, roll-mixing, co-milling, and spraying on sugar beads using a fluidized bed coating system for removal of organic solvents. ${ }^{13}$ Despite the great potential of solid dispersion systems for improving drug dissolution, the methods traditionally used for their preparation have serious limitations, often involving physical instability of the solid dispersions during storage, problems with grinding, or difficult removal of solvents. ${ }^{14-17}$ To address these issues, technology using supercritical fluids as an alternative solvent-evaporation method has been proposed to prepare solvent-free solid dispersions. ${ }^{18-20}$ Supercritical fluid technology represents a new and interesting route for particle formation that avoids most of the drawbacks of the transitional methods. ${ }^{20}$

A supercritical fluid can be defined as a substance existing as a single fluid phase above its critical temperature and pressure. Among the supercritical fluids, $\mathrm{CO}_{2}$ has been chosen based on its nontoxic, nonflammable, and inexpensive nature, its relatively high dissolving power, and its relatively low critical parameters $\left(\mathrm{T}_{\mathrm{c}}=31.1^{\circ} \mathrm{C}, \mathrm{P}_{\mathrm{c}}=73.8 \mathrm{bar}\right) .^{22}$ These properties make $\mathrm{CO}_{2}$ particularly attractive for processing heat-sensitive pharmaceuticals. The supercritical fluid process offers an alternative single-step method of particle formation capable of producing crystalline powders of microparticles or even nanoparticles with a narrow size distribution containing a minimum level of residual solvent. Depending on the specific process configuration, several additional advantages can exist, including high product purity, controlled crystal polymorphism, possible processing of thermolabile molecules, single-step process, easy downstream processing, and environmentally acceptable technology. ${ }^{23}$

The aim of this study was to develop solid dispersion nanoparticles for enhancement of the physicochemical properties and bioavailability of poorly water-soluble sirolimus, using the supercritical antisolvent (SAS) process. First, excipients for enhancing the stability and solubility of sirolimus were screened. Second, solid dispersions of sirolimus nanoparticles were prepared by the SAS process. Their physicochemical properties in the solid state were characterized by differential scanning calorimetry, powder X-ray diffraction, and scanning electron microscopy.
Kinetic solubility, dissolution, stability, and pharmacokinetics in rats were analyzed.

\section{Materials and methods}

Sirolimus was obtained from Beijing Everbright Science and Trading Co (Beijing, China; purity, 99.4\%). The $\mathrm{CO}_{2}$ with high purity of $99.99 \%$ was supplied by Hanmi Gas Co Ltd (Seoul, Korea). Everolimus (purity, 95.9\%) and zinc sulfate were purchased from Sigma-Aldrich (St Louis, MO). All organic solvents were high-pressure liquid chromatography (HPLC) grade. All other chemicals were reagent grade. Excipients used were hydroxypropyl cellulose (NISSO HPC-SSL and NISSO HPC-SL, Nippon Soda Co, Tokyo, Japan), hydroxypropylmethyl cellulose (HPMC 2910, Shin-Etsu Chemical Co Ltd, Tokyo, Japan), hydroxypropyl- $\beta$-cyclodextrin (HP- $\beta-C D$, Kleptose ${ }^{\circledR}$ HPB, Roquette, Lestrem, France), polyvinylpyrrolidone (PVP K17, PVP K25, PVP K30 and PVP K90, BASF Co Ltd, Ludwigshafen, Germany), polyvinylpyrrolidone vinyl acetate (PVP VA64, BASF Co Ltd), polyvinyl alcohol PEG graft copolymer (Kollicoat IR, BASF Co Ltd), ethylene oxide propylene oxide block copolymer (Poloxamer 188 and Poloxamer 407, BASF Co Ltd), lauryl macrogol 32 glyceride (Gelucire 44/14, Gattefossè, SaintPriest, France), stearoyl macrogol glyceride (Gelucire 50/13, Gattefossè), sucrose distearate (Sucroester 11, Gattefossè), sucrose monopalmitate (Sucroester 15, Gattefossè), d- $\alpha$ tocopheryl polyethylene glycol 1000 succinate (vitamin E TPGS, Eastman Co, Kingsport, TN), Eudragit EPO (Röhm GmbH and Co KG, Sontheim, Germany), PEG 4000, PEG 6000, and PEG 8000, Sigma), polyoxyethylene (40) monostearate (Myrj 52, Sigma), polyoxyethylene (50) monostearate (Myrj 53, Sigma), nicotinamide (Sigma), ascorbic acid (Sigma), citric acid (Sigma), meglumine (Sigma), glycine (Sigma), L-arginine (Sigma), sodium alginate (NSPH and NSPLL, Kibum Food Chemifa Co, Tokyo, Japan) and sodium lauryl sulfate (SLS, Ducsan Co Ltd, Seoul, Korea).

\section{Effect of excipients on solubility of sirolimus}

Solubility analysis was performed by adding excess sirolimus (5 mg) to a capped glass vial containing $3 \mathrm{~mL}$ of water with $1 \mathrm{mg} / \mathrm{mL}$ excipient. The samples were sonicated for $30 \mathrm{~min}$ utes at $37^{\circ} \mathrm{C}$ and placed in a shaking water bath (60 rpm) at $37^{\circ} \mathrm{C}$ for 3 days, which had been previously determined to be an adequate time for equilibration. At the end of this period, almost the entire volume $(2 \mathrm{~mL})$ was transferred to a clean tube and centrifuged at $15,000 \mathrm{rpm}$ for 20 minutes at $37^{\circ} \mathrm{C}$. The supernatant was filtered through a $0.45 \mu \mathrm{m}$ glass 
fiber syringe filter (GMF, Whatman, Clifton, NJ) using a glass syringe. The filtrate was diluted with methanol, and the sirolimus concentration was assayed by HPLC.

\section{Stability of sirolimus in dissolution medium}

The chemical stability of sirolimus was studied in several dissolution media commonly used in dissolution testing with a VK 7000 dissolution testing station and VK 750d heater/ circulator (Vankel, Cary, NC) at $37^{\circ} \mathrm{C}$. Simulated gastric ( $\mathrm{pH}$ 1.2) and intestinal fluids ( $\mathrm{pH}$ 6.8) were prepared according to USP XXVIII, and dissolution medium ( $\mathrm{pH} 4.0$ ) consisted of sodium acetate and acetic acid. Stability testing was carried out by adding a stock solution of sirolimus in dimethyl sulfoxide (DMSO) to $900 \mathrm{~mL}$ of dissolution medium, which had been equilibrated at the desired temperature for at least 1 hour. The initial concentration of sirolimus was $1 \mu \mathrm{g} / \mathrm{mL}$, and the DMSO concentration in the final solution was $0.11 \%$. Suitable aliquots were withdrawn at various time intervals, and the drug concentration was assayed by HPLC.

\section{Effect of excipients on stability of sirolimus}

To establish which excipients enhanced the stability of sirolimus, stability testing was performed by adding a stock solution of sirolimus in DMSO to a capped glass volumetric flask containing $50 \mathrm{~mL}$ of excipient dissolved in $\mathrm{pH} 1.2$ simulated gastric fluid at $1 \mathrm{mg} / \mathrm{mL}$ concentration. The initial concentration of sirolimus was $1 \mu \mathrm{g} / \mathrm{mL}$, and the DMSO concentration in the final solution was $0.11 \%$. The samples were placed in a water bath at $37^{\circ} \mathrm{C}$ in the dark. Suitable aliquots were withdrawn at various time intervals, and the drug concentration was assayed by HPLC.

\section{HPLC analysis}

HPLC analyses of in vitro samples of sirolimus were performed on a Waters ${ }^{\mathrm{TM}}$ HPLC system consisting of a pump (Model 600), an autosampler (Model 717 plus), and an ultraviolet detector (Model 486 tunable absorbance detector) using a previously reported method. ${ }^{24,25} \mathrm{~A} \mathrm{C}_{18}$ analytic column (Zorbax Eclipse XDB-C18, $5 \mu \mathrm{m}, 4.6 \mathrm{~mm} \times 250 \mathrm{~mm}$, Agilent, Santa Clara, CA) was used at $60^{\circ} \mathrm{C}$. The mobile phase was $84 \%$ methanol and $16 \%$ water. The injection volume was $20 \mu \mathrm{L}$ or $50 \mu \mathrm{L}$, and the eluent flow rate was $1.0 \mathrm{~mL} / \mathrm{minute}$. The signal was monitored at $278 \mathrm{~nm}$.

HPLC analyses of degradation products of sirolimus were performed on a Waters ${ }^{\mathrm{TM}}$ HPLC system consisting of a pump (Model 600), an auto-sampler (Model 717 plus), and an ultraviolet detector (Model 486), and a Shimadzu HPLC system (Kyoto, Japan) consisting of a LC-10ADvp pump, SIL-10A autosampler, and SPD-10ADvp UV detector using a previously reported method. ${ }^{26} \mathrm{~A}$ Supelcosil (Supelco, Bellefonte, PA) LC-18 column ( $4.6 \mathrm{~mm} \times 250 \mathrm{~mm}, 5 \mu \mathrm{m})$ was used. Separation of sirolimus and degradation products was achieved with a linear gradient from $65 \%$ to $86 \%$ methanol in $5 \mathrm{mM}$ ammonium acetate over 80 minutes at flow rate of $0.5 \mathrm{~mL} /$ minute. The injection volume was $50 \mu \mathrm{L}$ or $100 \mu \mathrm{L}$, and the signal was monitored at $276 \mathrm{~nm}$.

\section{Preparation of sirolimus solid-dispersion nanoparticles}

The SAS apparatus comprised the following components: two high pressure pumps; circulator and cooling lines for keeping the $\mathrm{CO}_{2}$ pump head and $\mathrm{CO}_{2}$ which flowed out of storage tank cold $\left(-10^{\circ} \mathrm{C}\right)$; a prevessel with an electric heating jacket; a precipitation vessel (1.9 L) with a water jacket and separator vessel (0.6 L); and two manual back pressure regulators (Model 26-1723-24-194; Tescom). Further information on the SAS apparatus has been published elsewhere. ${ }^{27}$ First, sirolimus and excipients were dissolved in organic solvents. Second, $\mathrm{CO}_{2}$ from a storage tank was delivered to the top of the particle precipitation vessel through the outer capillary of the two-flow spray nozzle at a constant rate, using a homemade plunger pump, until the desired pressure was obtained. After the pressure and temperature had equilibrated, the drug solution was introduced into the particle precipitation vessel by an HPLC liquid pump (Model 307; Gilson Inc, Middleton, WI) with supercritical $\mathrm{CO}_{2}$ through the inner capillary of the two-flow spray nozzle. The residual solvent (supercritical $\mathrm{CO}_{2}$ and organic solvents) was drained out of the particle precipitation vessel by the back pressure regulator. At the washing step, additional supercritical $\mathrm{CO}_{2}$ continued to flow into the precipitation vessel to wash out the residual organic solvents solubilized in the SAS. The precipitation vessel was slowly depressurized to atmospheric pressure, and finally, the particles were collected from the internal basket of the precipitation vessel (retained by a metal frit and paper filter).

\section{In vitro characterization of sirolimus solid dispersion nanoparticles}

The drug content in the processed samples was determined by HPLC. A sample of approximately $20 \mathrm{mg}$ was dissolved in $100 \mathrm{~mL}$ of methanol or methanol/dichloromethane (1:1). Analysis of the residual solvents was carried out on a Shimadzu 2010 model gas chromatograph equipped with a 
flame ionization detection system. A DB-5 capillary column (30 $\mathrm{m} \times 0.32 \mathrm{~mm}$ ID; film thickness, $0.25 \mu \mathrm{m}$ ) was used. The samples were dissolved in dimethylformamide. Butanol was used as an internal standard. Quantification was performed using a calibration curve.

Particle morphology was observed using a scanning electron microscope (JSM-7000F; Jeol Ltd, Tokyo, Japan). Samples were coated with gold and palladium using a vacuum evaporator and were examined at an accelerating voltage of $5 \mathrm{kV}$.

The particle size and particle size distribution of samples were determined by dynamic light scattering using an electrophoretic light scattering spectrophotometer (ELS-8000; Otsuka Electronics, Hirakata, Japan). The samples were dispersed in mineral oil (Macrol 52; Exxon Mobil Co, Baltimore, MD) and sonicated for 10 minutes at $120 \mathrm{~W}$ (Branson 8210; Branson Ultrasonics Co, Danbury, CT). We obtained information about particle size by analyzing dynamic light scattering data using the cumulant method.

Powder X-ray diffraction patterns were recorded on a Rigaku powder X-ray diffraction system (Model D/MAX2200; Ultima/PC, Japan) with Ni-filtered $\mathrm{Cu}-\mathrm{K} \alpha$ radiation. The samples were analyzed over the most informative range, from $5^{\circ}$ to $60^{\circ}$ of $2 \theta$. The step scan mode was used with a step size of $0.02^{\circ}$ at a rate of $3^{\circ}$ per minute.

Differential scanning calorimetry measurements were conducted using a differential scanning calorimetry S-650 (Scinco Co Ltd, Seoul, Korea). Samples of 2-3 mg were accurately weighed and sealed in aluminum. The measurements were performed under nitrogen purge over $20^{\circ} \mathrm{C}-250^{\circ} \mathrm{C}$ at a heating rate of $5^{\circ} \mathrm{C} /$ minute. An empty pan was used for reference, and the differential scanning calorimetry baseline, temperature, and enthalpy were calibrated with indium before each experiment, at a heating rate of $5^{\circ} \mathrm{C} /$ minute. A nitrogen flow rate of $20 \mathrm{~mL} / \mathrm{minute}$ was used for each differential scanning calorimetry run.

The specific surface area of the samples was determined by nitrogen adsorption using a surface area analyzer (ASAP 2010; Micromeritics Instrument Corporation, Atlanta, GA).

For kinetic solubility studies, excess solid (approximately $20 \mathrm{mg}$ of sirolimus) was placed in $100 \mathrm{~mL}$ of degassed water in a glass flask at $37^{\circ} \mathrm{C} \pm 0.1^{\circ} \mathrm{C}$. The samples were placed in a shaking water bath at $60 \mathrm{rpm}$ and $37^{\circ} \mathrm{C} \pm 0.1^{\circ} \mathrm{C}$. Suitable aliquots were withdrawn at various time intervals using a glass syringe. Approximately $2 \mathrm{~mL}$ aliquots were transferred to clean tubes and centrifuged at 15,000 rpm for 10 minutes at $37^{\circ} \mathrm{C}$. The supernatants were filtered through a $0.45 \mu \mathrm{m}$ glass fiber syringe filter (GMF, Whatman) and diluted with methanol. The concentration of sirolimus was determined by HPLC.

Dissolution studies were performed according to the USP XXVIII paddle method using a VK 7000 dissolution testing station and VK 750d heater/circulator (Vankel). The stirring speed was $50 \mathrm{rpm}$, and the temperature was maintained at $37^{\circ} \mathrm{C} \pm 0.1^{\circ} \mathrm{C}$. Each test was carried out in $900 \mathrm{~mL}$ of degassed water. Accurately weighed samples containing the equivalent of $2 \mathrm{mg}$ sirolimus were placed in the dissolution medium. Then, $4 \mathrm{~mL}$ aliquots were withdrawn at various time intervals and filtered using a $0.45 \mu \mathrm{m}$ GMF filter. At each sampling time, an equal volume of the test medium was replaced. Filtered samples were appropriately diluted with methanol, and the drug concentration was assayed by HPLC.

Sirolimus powder or solid dispersion nanoparticles were spread uniformly on a glass plate to allow uniform irradiation. The samples were positioned $30 \mathrm{~cm}$ below the ultraviolet lamps (UVA 315-400 nm, 89.2 W; UVB 280-315 nm, 6.5 W; Ultra Vitalux ${ }^{\circledR}$ and Eversun ${ }^{\circledR}$, Osram, Munich, Germany) inside a stability chamber to protect the samples from extraneous light, and exposed to ultraviolet irradiation for $0-48$ hours at $25^{\circ} \mathrm{C} \pm 2{ }^{\circ} \mathrm{C}$ and $60 \% \pm 5 \%$ relative humidity. Samples were taken at 12, 24, 36, and 48 hours, and the photodegradation of sirolimus in each sample was monitored using HPLC.

To evaluate the stability of the sirolimus solid dispersion nanoparticles, each sample was placed in an airtight brown vial and stored at $25^{\circ} \mathrm{C} \pm 2{ }^{\circ} \mathrm{C}$ and $60 \% \pm 5 \%$ relative humidity. The powder dissolution in water and X-ray diffraction patterns of each sample were examined periodically.

\section{In vivo characterization of sirolimus solid dispersion nanoparticles}

Male Sprague-Dawley rats weighing 200-220 g were obtained from Samtaco Bio Korea Inc (Osan, Korea). All rats had free access to tap water and a pelleted diet. The rats were housed in cages and maintained on a 12-hour light/dark cycle at room temperature $\left(25^{\circ} \mathrm{C}\right)$ and $55 \% \pm 10 \%$ relative humidity. General and environmental conditions were strictly monitored. The study protocol was approved by the ethics committee of Chungnam National University. All animal experiments were performed according to the Guidelines for the Care and Use of Laboratory Animals at Chungnam National University.

The rats were deprived of food for 24 hours before the experiment, and food was reoffered at 4 hours post-dosing. After anesthesia with diethylether, the femoral artery was 
cannulated with a 23 gauge polyethylene cannula. The cannula was flushed with $0.3 \mathrm{~mL}$ of heparin (50 IU) saline solution to prevent blood clotting. After the rats had recovered from anesthesia, sirolimus powder and solid dispersion nanoparticles were administered by oral gavage at a sirolimus dose of $10 \mathrm{mg} / \mathrm{kg}$. Each formulation was dispersed in $5 \mathrm{~mL} / \mathrm{kg}$ $(0.2 \% \mathrm{w} / \mathrm{v})$ aqueous methylcellulose immediately before dosing. Serial blood samples (approximately $500 \mu \mathrm{L}$ each) were collected from the femoral artery before dosing and at 20 and 40 minutes, and 1, 1.5, 2, 3, 5, 8, and 12 hours postdosing. Blood samples were transferred to individual Eppendorf tubes containing $20 \mu \mathrm{L}$ of ethylenediamine tetra-acetic acid $(2.5 \% \mathrm{w} / \mathrm{v})$ and stored at $-80^{\circ} \mathrm{C}$ until analyzed. Liquid chromatography-mass spectrometry (LC-MS) analysis was performed within one week after blood sampling.

The sirolimus concentration in the blood samples was determined by LC-MS as reported previously, with slight modifications. ${ }^{28-30}$ Whole-blood samples $(400 \mu \mathrm{L})$ were extracted by vortex mixing for 60 seconds with $400 \mu \mathrm{L}$ of methanol, $400 \mu \mathrm{L}$ of $6.25 \%(\mathrm{w} / \mathrm{v})$ zinc sulfate, and $40 \mu \mathrm{L}$ of internal standard solution $(1 \mu \mathrm{g} / \mathrm{mL}$ everolimus in $50 \%$ methanol). Precipitated materials were separated by centrifugation $\left(13,000 \mathrm{rpm}\right.$ for 10 minutes at $\left.1^{\circ} \mathrm{C}\right)$, and the supernatants were transferred to clean tubes. $\mathrm{NaOH}(100 \mu \mathrm{L}, 0.1 \mathrm{M})$ was added to each tube, followed by vortex mixing. Next, 1-chlorobutane was added to the sample tubes. The phases were separated by centrifugation $(13,000 \mathrm{rpm}$ for 10 minutes at $1^{\circ} \mathrm{C}$ ), and the organic phase was removed and evaporated to dryness under nitrogen at $40^{\circ} \mathrm{C}$ for 10 minutes. The residue was reconstituted in $100 \mu \mathrm{L}$ of $70 \%$ methanol, and $10 \mu \mathrm{L}$ of each sample were analyzed by LC-MS. The LC-MS system consisted of an LC-10ADvp pump, SIL-10A autoinjector, SPD-10ADvp ultraviolet detector, and LCMS-2010A mass spectrometer. Sirolimus was analyzed on a Supelcosil LC-18 column $(150 \times 4.6 \mathrm{~mm}, 3 \mu \mathrm{m})$ maintained at $60^{\circ} \mathrm{C}$, with Supelguard LC-18 (2 cm cartridge) as a precolumn. The mobile phase was $70 \%$ acetonitrile and was pumped at a flow rate of $1.0 \mathrm{~mL} /$ minute. The detection wavelength was $276 \mathrm{~nm}$. The mass spectrometer was operated in positive ion mode and was connected to the chromatographic system using an atmospheric pressure ionization electrospray inter-

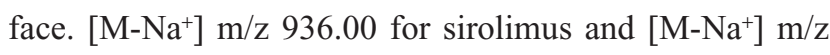
980.00 for everolimus were selected as the detecting ions, respectively. The mass spectrometry operating conditions were optimized as follows: drying gas, $1.5 \mathrm{~L} /$ minute; $\mathrm{CDL}$ temperature, $250^{\circ} \mathrm{C}$; block temperature, $200^{\circ} \mathrm{C}$; and probe voltage, $+4.5 \mathrm{kV}$. Data processing was performed using LC-MS Solution software (Shimadzu). Sirolimus blood concentrations were quantified by comparison with standard curves generated from spiked blood samples extracted in the same manner as for the test samples. Standard curve samples $(5-500 \mathrm{ng} / \mathrm{mL})$ were prepared fresh on each day of analysis and were linear over the range tested, with $R^{2}>0.99$.

\section{Pharmacokinetic data analysis}

The $\mathrm{AUC}_{0 \rightarrow 12 \mathrm{~h}}$ and mean residence time were calculated using noncompartmental analysis (WinNonlin 2.1; Pharsight Corporation, Mountain View, CA). The peak concentration $\left(\mathrm{C}_{\max }\right)$ and time taken to reach peak concentration $\left(\mathrm{T}_{\max }\right)$ were obtained directly from blood data. To demonstrate statistically significant differences, one-way analysis of variance followed by least-squares difference test and the StudentNewman-Keul test was performed, using SPSS software (v 12.0; SPSS Inc, Chicago, IL).

\section{Results and discussion Screening of excipients}

The excipients were chosen to provide a diversity of structural and physicochemical properties, and were not selected based on any specific hypotheses regarding their likely interactions with the formulation components. The polymers studied included cellulose derivatives (methyl cellulose, HPC, HPMC), PVP, PEG, alginate, and alginate derivatives. Although all the selected surfactants, except SLS, were nonionic, they still represented a wide diversity of functional hydrophilic and hydrophobic groups, as well as surfactant architectures, molecular weights, and melting points. In addition, a hydrotropic agent (nicotinamide), three organic acid/ base candidates (citric acid, ascorbic acid, and meglumine), and two sugars (sucrose and mannitol) were studied.

The solubilization effect of the surfactants was greater than that of the polymers, possibly due to the formation of micelles. Each type of surfactant tested had a different solubilization capacity attributable to its particular structure, properties, and interaction with sirolimus. As shown in Figure 1, the most effective solubilizing excipient was SLS, followed by Sucroester 15, TPGS, Gelucire 50/13, and Myrj 52.

The stability of sirolimus and the effects of excipients on its stability were studied. First, the stability test of sirolimus was performed in different dissolution media using a paddle method as the dissolution apparatus. As shown in Figure 2, the remaining percentage of sirolimus was decreased in different dissolution media with different degradation kinetics. In particular, rapid degradation of sirolimus was observed in $\mathrm{pH} 1.2$ dissolution medium, and the amount of sirolimus remaining was $<10 \%$ at 30 minutes. 


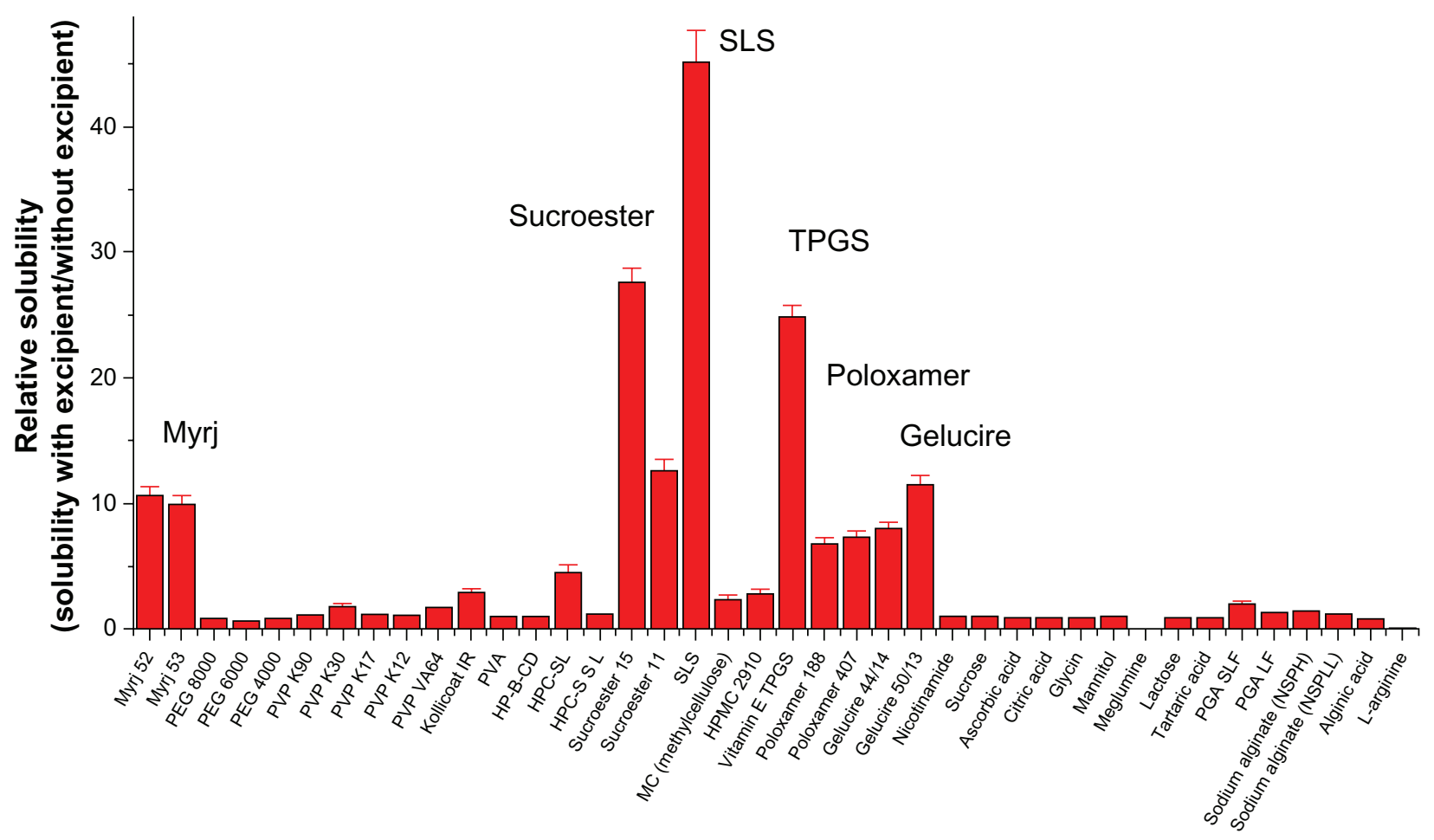

Figure I Screening of excipients for improving the solubility of sirolimus.

Note: Data are expressed as the mean \pm standard deviation $(n=2-3)$.

Abbreviations: PEG, polyethylene glycol; PVP, polyvinylpyrrolidone; HPMC, hydroxypropylmethyl cellulose; HPC, hydroxypropyl cellulose; HP- $\beta$-CD, hydroxypropyl- $\beta$ cyclodextrin; SLS, sodium lauryl sulfate; TPGS, d- $\alpha$-tocopheryl polyethylene glycol 1000 succinate; PVA, polyvinyl alcohol; PGA, polyglycolic acid; SL, sirolimus.

The degradation peaks increased with time. Semilogarithmic plots of the remaining sirolimus versus time in different dissolution media (Figure 2) indicated pseudo first-order degradation behavior:

$$
\log [C]_{t}=\log \left[C_{0}\right]-\frac{k_{o b s}}{2.303} t
$$

where $\left[C_{0}\right]$ is the initial concentration of sirolimus and $[C]_{t}$ is the percentage remaining at time $t$, which allowed calculation of the degradation pseudo first-order rate constants $\left(k_{o b s}\right)$ as the slopes of the lines obtained by linear regression analysis. The half-life $\left(t_{1 / 2}\right)$ was calculated according to equation (2)

$$
t_{1 / 2}=0.693 / k_{o b s}
$$

The values of $k_{\text {obs }}$ and $t_{1 / 2}$ are shown in Table 1.

Sirolimus is practically insoluble in water and contains no functional groups that are ionizable in the $\mathrm{pH}$ range $1-10 .^{3}$ Given the rapid degradation of sirolimus in $\mathrm{pH} 1.2$ dissolution medium, the effects of excipients on the stability of sirolimus in $\mathrm{pH} 1.2$ dissolution medium were investigated. The effects of the different excipients on the stability of sirolimus are presented in Figure 2 and Table 2. Among the excipients, surfactants (surface-active carriers) enhanced the stabilization of sirolimus to a significantly greater degree than did the hydrophilic polymers. Sucrose and hydrophilic polymers such as PVP, PVP VA64, HPMC, and HPC did not significantly enhance the stability of sirolimus at a concentration of $1 \mathrm{mg} / \mathrm{mL}$. Eudragit EPO, which is soluble at an acid $\mathrm{pH}$, significantly increased the stability of sirolimus, and the pseudo first-order rate constant of sirolimus with Eudragit EPO was decreased approximately four-fold compared with that of sirolimus alone. Previously, Rouf et $\mathrm{al}^{5}$ reported that the stability problems observed for sirolimus in different light, temperature, buffer, and ionic conditions may be avoided by complexation with $\beta$-cyclodextrin. However, in the present study, hydroxypropyl $\beta$-cyclodextrin did not significantly enhance the stability of sirolimus $(1 \mathrm{mg} / \mathrm{mL})$ in $\mathrm{pH} 1.2$ dissolution medium. The stabilization effect of the surfactants was greater than that of the polymers, possibly due to micelle formation, and each surfactant tested had a different solubilization capacity owing to its specific structure, properties, and interaction with sirolimus. The long-chain hydrophobic moiety of surfactants showed a greater stabilization effect than poloxamers and Gelucires. The most effective stabilizer in $\mathrm{pH}$ 1.2 dissolution medium was TPGS, followed by Sucroester 15, Gelucire 50/13, and Myrj 52. However, further study of the stabilization mechanism for the excipients is needed. 

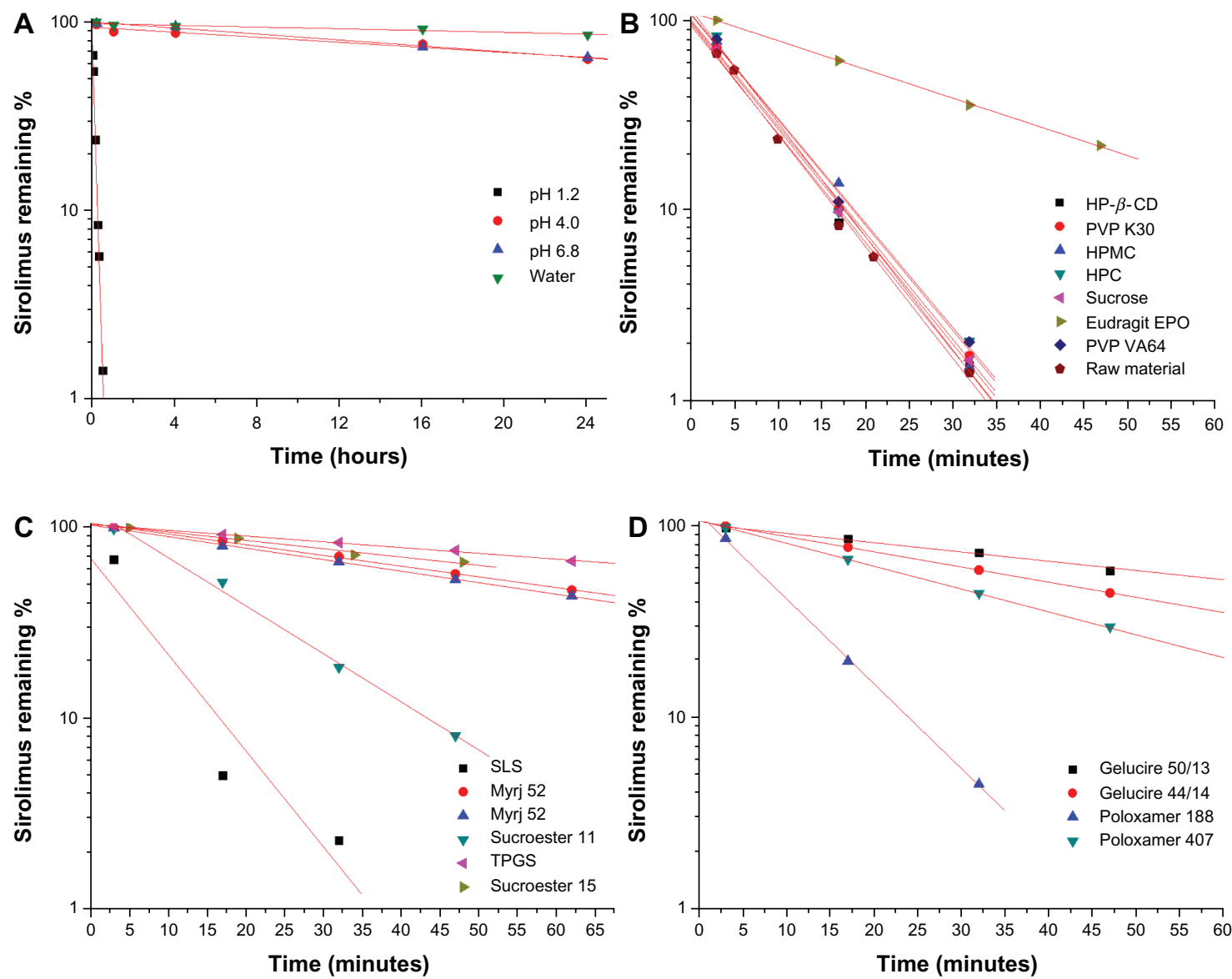

Figure 2 Stability of sirolimus in dissolution medium (A) and effect of excipients on stability of sirolimus (B, C, and D).

Note: Data are expressed as the mean value $(n=2-3)$.

Abbreviations: PEG, polyethylene glycol; PVP, polyvinylpyrrolidone; HPMC, hydroxypropylmethyl cellulose; HPC, hydroxypropyl cellulose; HP- $\beta$-CD, hydroxypropyl- $\beta$ cyclodextrin; SLS, sodium lauryl sulfate; TPGS, d- $\alpha$-tocopheryl polyethylene glycol 1000 succinate.

\section{Characterization of sirolimus solid dispersion nanoparticles}

In preliminary experiments, solid dispersions of sirolimus were prepared using hydrophilic carriers such as HPMC 2910, PVP K30, PVP VA64, HPC-SSL, HPC-SL, PEG 6000, and PEG 8000 at $20 \%$ drug: $80 \%$ polymer $(\mathrm{w} / \mathrm{w})$ with ethanol or an ethanol-dichloromethane mixture as a solvent. The operating conditions used in our experiments were selected on the basis of our previous experience with the SAS process. For the particle precipitation vessel, the conditions were $40^{\circ} \mathrm{C}$

Table I Stability of sirolimus in dissolution medium

\begin{tabular}{llrl}
\hline Medium $\left(37^{\circ} \mathbf{C}\right)$ & $\boldsymbol{k}_{\text {obs }}$ (per hour) & \multicolumn{1}{c}{$\boldsymbol{t}_{1 / 2}$ (hours) } & \multicolumn{1}{l}{$\boldsymbol{R}^{\mathbf{2}}$} \\
\hline PH I.2 & $8.0804 \pm 0.5180$ & $0.09 \pm 0.01$ & 0.9959 \\
PH 4.0 & $0.0153 \pm 0.0012$ & $45.18 \pm 3.56$ & 0.9547 \\
PH 6.8 & $0.0182 \pm 0.0012$ & $37.99 \pm 2.53$ & $0.994 I$ \\
Water & $0.0054 \pm 0.0004$ & $129.15 \pm 9.01$ & 0.9003 \\
\hline
\end{tabular}

Note: Data are expressed as the mean \pm standard deviation $(n=2-3)$.

Abbreviations: $k_{o b s}$, pseudo first-order rate constants; $t_{1 / 2}$, half-life period; $R^{2}$, determination coefficient. and $12 \mathrm{MPa}$. In PEG-sirolimus formulations with a drug/ polymer ratio of $20 \%: 80 \%$, the yields were low $(<10 \%)$, and few solid dispersion particles could be collected. In addition, PEG-sirolimus formulations gave irregular microparticles in the size range of 1-20 $\mu \mathrm{m}$. Furthermore, the PVP VA64sirolimus formulation resulted in formation of no particles during the SAS process. This might have been attributable to the lower glass transition temperature of PEG 6000 and 8000 and PVP VA64 when using $\mathrm{CO}_{2}$ as a plasticizer. ${ }^{31}$ Among these hydrophilic polymers, PVP K30 was chosen for further study because it formed a homogeneous matrix.

\section{Effect of surfactants}

The experimental conditions and results of the SAS process are summarized in Table 3. As shown in Figure 3, PVP K30-sirolimus nanoparticles with a mean particle size of approximately $400 \mathrm{~nm}$ were obtained using the SAS process. Formulations of PVP K30-sirolimus with SLS, or Sucroester 15 produced spherical fine particles. However, when 
Table 2 Effect of excipients on stability of sirolimus in a dissolution medium of $\mathrm{pH} \mathrm{I} .2$

\begin{tabular}{|c|c|c|}
\hline Excipients & $k_{o b s}$ (per minute) & $t_{1 / 2}$ (minutes) \\
\hline Raw material & $0.1347 \pm 0.0086$ & $5.15 \pm 0.33$ \\
\hline PVP K30 & $0.1283 \pm 0.0070$ & $5.40 \pm 0.29$ \\
\hline PVP VA64 & $0.1259 \pm 0.0070$ & $5.50 \pm 0.30$ \\
\hline HPMC 2910 & $0.1322 \pm 0.0079$ & $5.24 \pm 0.31$ \\
\hline HPC & $0.1268 \pm 0.0073$ & $5.46 \pm 0.31$ \\
\hline Eudragit EPO & $0.0346 \pm 0.0016$ & $20.03 \pm 0.95$ \\
\hline $\mathrm{HP}-\beta-\mathrm{CD}$ & $0.1307 \pm 0.0078$ & $5.30 \pm 0.32$ \\
\hline Sucrose & $0.1295 \pm 0.0076$ & $5.35 \pm 0.31$ \\
\hline Poloxamer I88 & $0.1018 \pm 0.0053$ & $6.81 \pm 0.35$ \\
\hline Poloxamer 407 & $0.0275 \pm 0.0013$ & $25.22 \pm 1.17$ \\
\hline Gelucire 44/I4 & $0.0182 \pm 0.0008$ & $37.99 \pm 1.65$ \\
\hline Gelucire $50 / 13$ & $0.0111 \pm 0.0005$ & $62.30 \pm 2.83$ \\
\hline Myrj 52 & $0.0129 \pm 0.0006$ & $53.64 \pm 2.43$ \\
\hline Myrj 53 & $0.0139 \pm 0.0006$ & $49.99 \pm 2.31$ \\
\hline Sucroester II & $0.0579 \pm 0.0030$ & $11.96 \pm 0.62$ \\
\hline Sucroester 15 & $0.0101 \pm 0.0005$ & $68.86 \pm 3.49$ \\
\hline SLS & $0.1160 \pm 0.0076$ & $5.98 \pm 0.39$ \\
\hline TPGS & $0.0070 \pm 0.0004$ & $99.64 \pm 5.72$ \\
\hline
\end{tabular}

surfactants such as TPGS, Gelucire 50/13, or Myrj 52 were added to the PVP K30-sirolimus formulation, the particle size was increased, and particle aggregation was observed in scanning electron microscopy images (Figure 3), owing to the lower melting temperatures of these surfactants. ${ }^{32}$

\section{Solid state characterization}

The solid state of sirolimus solid dispersion nanoparticles was characterized by powder X-ray diffraction and differential scanning calorimetry. Figure 4 shows the differential scanning calorimetry thermograms and X-ray diffraction patterns of the raw material and of PVP K30-sirolimus nanoparticles prepared by the SAS process with and without various surfactants. Sirolimus exhibited two endothermic bands around $187^{\circ} \mathrm{C}$ and $193^{\circ} \mathrm{C}$, at a heating rate of $10^{\circ} \mathrm{C} /$ minute. In contrast, no endothermic peaks corresponding to sirolimus were observed in nanoparticles prepared using the SAS process. The broad endothermic bands observed on the differential scanning calorimetry thermograms of PVP K30 or PVP K30/surfactant were associated with water loss from amorphous PVP K30 and the characteristic melting peaks of surfactants. The diffraction pattern of sirolimus showed characteristic high-intensity peaks at $7.2,9.9,10.2,11.1,12.5,14.5,15.3,15.5,16.2$, 20.0, 20.4, and 21.8 degrees of $2 \theta$. On the other hand, the powder X-ray diffraction patterns of nanoparticles prepared by the SAS process were completely different from those of the raw material and did not show any characteristic diffraction peaks corresponding to sirolimus. These data confirm that sirolimus was present in an amorphous form within the nanoparticles.

\section{Kinetic solubility}

Figure 5 shows the kinetic solubility profiles of the raw material and sirolimus solid dispersion nanoparticles prepared by the SAS process. The maximum solubility of nanoparticles prepared by the SAS process was $40-200 \mu \mathrm{g} / \mathrm{mL}$, and the solubility at 24 hours was $3-110 \mu \mathrm{g} / \mathrm{mL}$. In the case of PVP K30-SLS-sirolimus nanoparticles, the maximum solubility of sirolimus was much higher than that of other formulations. However, for PVP K30-Sucroester

Table 3 Process conditions and results with the supercritical antisolvent process

\begin{tabular}{|c|c|c|c|c|}
\hline \multirow[t]{2}{*}{ Formulation (weight) } & \multirow{2}{*}{$\frac{\text { Process parameter }}{\text { Solvent }^{\mathrm{a}}}$} & \multicolumn{3}{|l|}{ Results } \\
\hline & & Drug content $^{\mathrm{b}}$ & Mean particle size ${ }^{c}$ & Specific surface area ${ }^{c}$ \\
\hline SR:PVP K30 = 20:80 & $\mathrm{DCM} / \mathrm{EtOH}$ & $13.67 \pm 1.05 \%$ & $245 \pm 72 \mathrm{~nm}$ & $45.88 \pm 0.45 \mathrm{~m}^{2} / \mathrm{g}$ \\
\hline SR:PVP K30:TPGS = 20:60:20 & $\mathrm{DCM} / \mathrm{EtOH}$ & $13.47 \pm 0.53 \%$ & $650 \pm 151 \mathrm{~nm}$ & $18.32 \pm 0.32 \mathrm{~m}^{2} / \mathrm{g}$ \\
\hline SR:PVP K30:SLS = 20:60:20 & $\mathrm{EtOH}$ & $12.82 \pm 0.55 \%$ & $352 \pm 132 \mathrm{~nm}$ & $30.56 \pm 0.35 \mathrm{~m}^{2} / \mathrm{g}$ \\
\hline SR:PVP K30:SEI5 = 20:60:20 & $\mathrm{DCM} / \mathrm{EtOH}$ & $15.03 \pm 1.01 \%$ & $302 \pm 102 \mathrm{~nm}$ & $35.17 \pm 0.54 \mathrm{~m}^{2} / \mathrm{g}$ \\
\hline SR:PVP K30:G50 = 20:60:20 & $\mathrm{DCM} / \mathrm{EtOH}$ & $15.52 \pm 0.98 \%$ & $453 \pm 95 \mathrm{~nm}$ & $21.36 \pm 0.35 \mathrm{~m}^{2} / \mathrm{g}$ \\
\hline SR:PVP K30:M52 = 20:60:20 & $\mathrm{DCM} / \mathrm{EtOH}$ & $14.00 \pm 1.05 \%$ & Irregular microparticles & ND \\
\hline Unprocessed drug & - & - & $53.5 \pm 3.2 \mu \mathrm{m}$, irregular & $3.21 \pm 0.15 \mathrm{~m}^{2} / \mathrm{g}$ \\
\hline
\end{tabular}

Notes: Sirolimus solid dispersion nanoparticles were prepared at $40^{\circ} \mathrm{C}$ and $12 \mathrm{MPa}$. The flow rates of supercritical $\mathrm{CO}_{2}$ and drug solution were $45 \mathrm{~g} / \mathrm{minute}$ and $0.5 \mathrm{~g} /$ minute, respectively. This position of the operating point is in the supercritical region and very far from the mixture critical point pressure on vapor-liquid equilibrium data of each solvent- $\mathrm{CO}_{2}$. These operating conditions ensured complete miscibility between the organic solvent and $\mathrm{CO}_{2}$. ${ }^{\mathrm{a}} \mathrm{DCM} / \mathrm{EtOH}(50: 50$, w/w) or EtOH was chosen because it dissolved PVP and surfactants. Gas chromatographic analysis revealed that residual solvent (dichloromethane) in the solid dispersion nanoparticles prepared by the supercritical antisolvent process has been routinely checked for all samples and found to be always below 50 ppm in our study. The drug content (\%) = mass of loaded drug/ total mass of the particle $\times 100$; bdata are expressed as the mean \pm standard deviation $(n=2-3)$; 'data are expressed as the mean \pm standard deviation $(n=3)$.

Abbreviations: SR, sirolimus; SE I5, Sucroester I5; M52, Myrj 52; G50, Gelucire 50/ I 3; DCM, dichloromethane; EtOH, ethanol; ND, not determined; PVP, polyvinylpyrrolidone; SLS, sodium lauryl sulfate. 

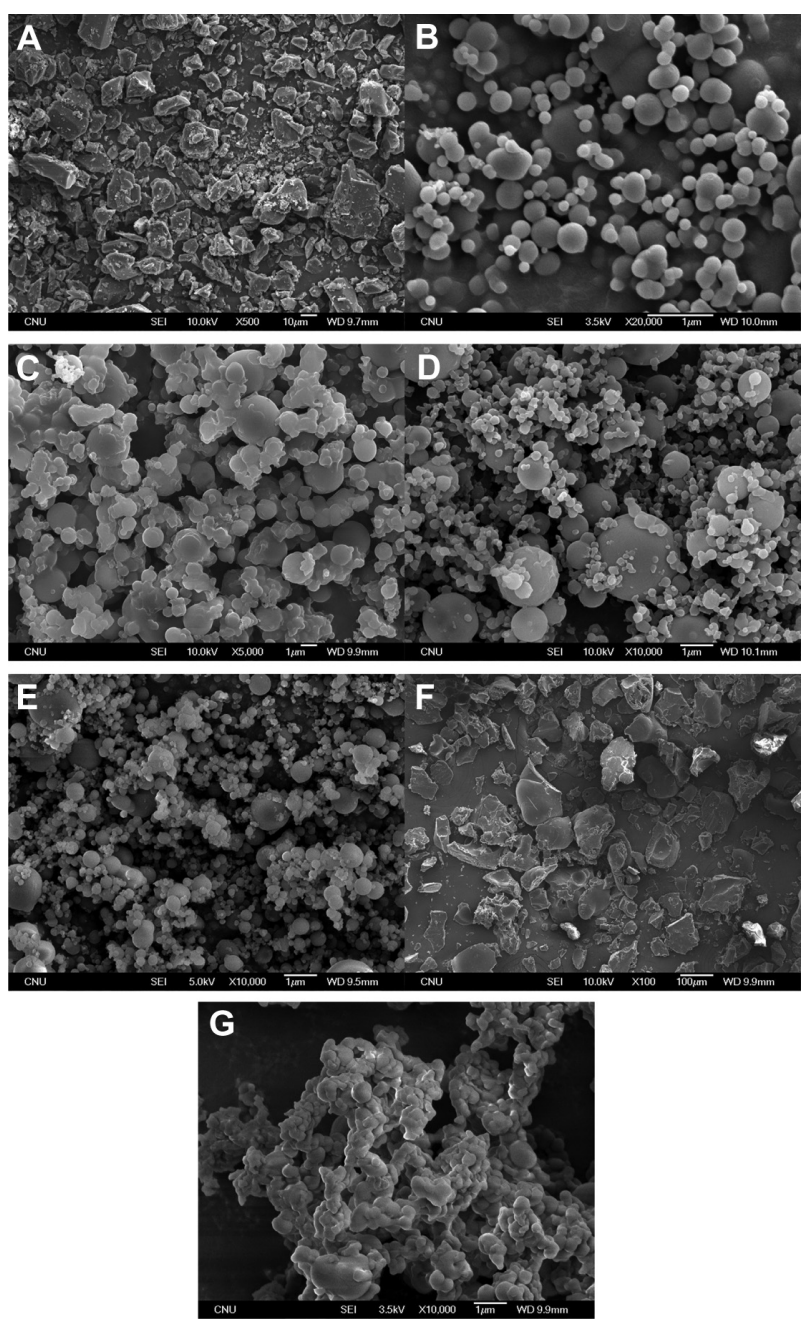

Figure 3 Scanning electron microscopic images of raw material (A) and sirolimus solid dispersion nanoparticles prepared by the supercritical antisolvent process: SR-PVP K30 (B), SR-PVP K30-TPGS (C), SR-PVP K30-SLS (D), SR-PVP K30-Sucroester I5 (E), SR-PVP K30-Myrj 52 (F), SR-PVP K30-Gelucire 50/I3 (G). Abbreviations: SR, sirolimus; PVP, polyvinylpyrrolidone; TPGS, d- $\alpha$-tocopheryl polyethylene glycol 1000 succinate.

15-sirolimus and PVP K30-TPGS-sirolimus nanoparticles, the solubility of sirolimus at 24 hours was much higher than that of other formulations. For supersaturated drugs that precipitate out, the decrease in drug solubility can be prevented by micelle formation with a surfactant. The drug may be molecularly dispersed in the excipient matrix (solid solution), or may occur as fine nanocrystalline or amorphous particles that form during the SAS process. After a solid dispersion formulation (especially solid solution) has dissolved, the drug will be present as a supersaturated solution. Some formulations (polymer and/or surfactant) may serve to inhibit precipitation of the drug from a supersaturated solution, while with other formulations the drug may precipitate out as a metastable polymorph with higher solubility than that of the most stable form. ${ }^{33,34}$ Therefore, the key factor for an effective solid dispersion formulation is a higher supersaturation concentration for a prolonged time. In the present study, PVP K30-sirolimus nanoparticles containing SLS, TPGS, or Sucroester 15 were effective formulations for a higher supersaturation concentration of sirolimus over a prolonged time.

\section{Powder dissolution}

The powder dissolution profiles of the raw material and PVP K30-sirolimus with and without surfactants are shown in Figure 6. The drug was approximately $95 \%$ dissolved for PVP K30-sirolimus with surfactants, whereas only approximately $5 \%$ of the unprocessed drug was dissolved at 30 minutes. This can be explained by the enhanced supersaturation and an increased specific surface area resulting from reduced particle size of the PVP K30-sirolimus with surfactants in comparison with unprocessed drug.

\section{Pharmacokinetics in rats}

The bioavailability of sirolimus nanoparticle formulations was evaluated in rats. Figure 7 shows the blood concentration-time profile of sirolimus in rats after oral administration of SASprocessed samples at a dose equivalent to $10 \mathrm{mg} / \mathrm{kg}$ sirolimus. The pharmacokinetic parameters calculated from the time profiles are presented in Table 4 . For the raw material $(0.2 \%$ $\mathrm{w} / \mathrm{v}$ methyl cellulose as suspension), the $\mathrm{AUC}_{0 \rightarrow 12 \mathrm{~h}}, \mathrm{C}_{\max }$, and $\mathrm{T}_{\max }$ were $101.3 \pm 14.4 \mathrm{ng} \cdot \mathrm{h} / \mathrm{mL}, 15.9 \pm 4.4 \mathrm{ng} / \mathrm{mL}$, and $3.8 \pm 1.5$ hours, respectively. After the administration of PVP K30-sirolimus nanoparticles, the $\mathrm{AUC}_{0 \rightarrow 12 \mathrm{~h}}, \mathrm{C}_{\max }$, and $\mathrm{T}_{\max }$ were $601.7 \pm 121.2 \mathrm{ng} \cdot \mathrm{h} / \mathrm{mL}, 129.8 \pm 13.9 \mathrm{ng} / \mathrm{mL}$, and $1.0 \pm 0.4$ hours, respectively. Furthermore, the bioavailability of sirolimus was significantly increased with the addition of surfactants. In particular, PVP K30-SLS-sirolimus nanoparticles showed higher bioavailability than the raw material, with approximately 15.2-fold and 18.3-fold increases in $\mathrm{AUC}_{0 \rightarrow 12 \mathrm{~h}}$ and $\mathrm{C}_{\max }$. Based on one-way analysis of variance, there were significant differences among the samples $(P<0.05)$, which were ranked by the Student-Newman-Keul test in order of increasing $\mathrm{AUC}_{0 \rightarrow 12 \mathrm{~h}}$ as follows: raw material < PVP K30 and PVP K30-Gelucire 50/13 $(P=0.331)<$ PVP K30-TPGS, PVP K30-Sucroester 15, and PVP K30-SLS $(P=0.055)$. In fact, the $\mathrm{AUC}_{0 \rightarrow 12 \mathrm{~h}}$ and $\mathrm{C}_{\max }$ of sirolimus increased with supersaturation concentration. The bioavailability of PVP K30-sirolimus nanoparticles with surfactants was markedly higher than that of PVP K30-sirolimus nanoparticles 
A

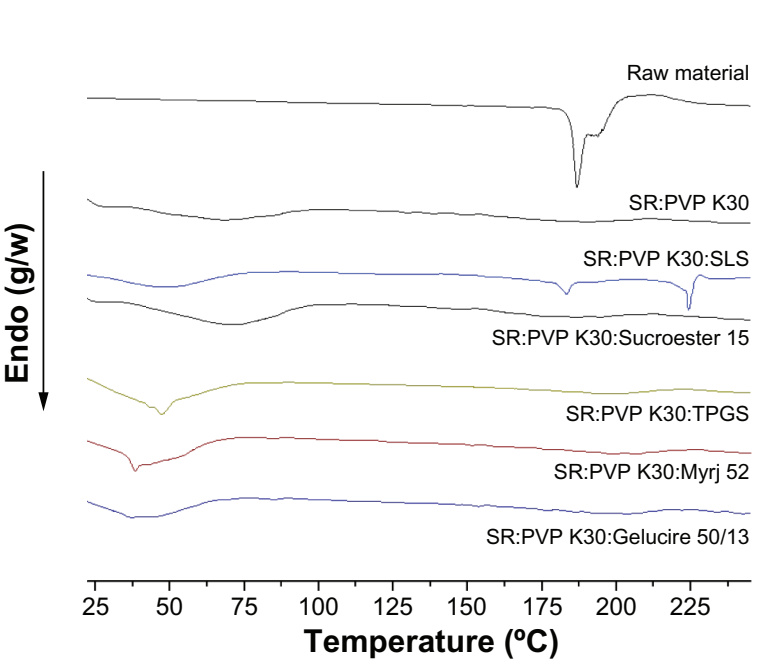

B

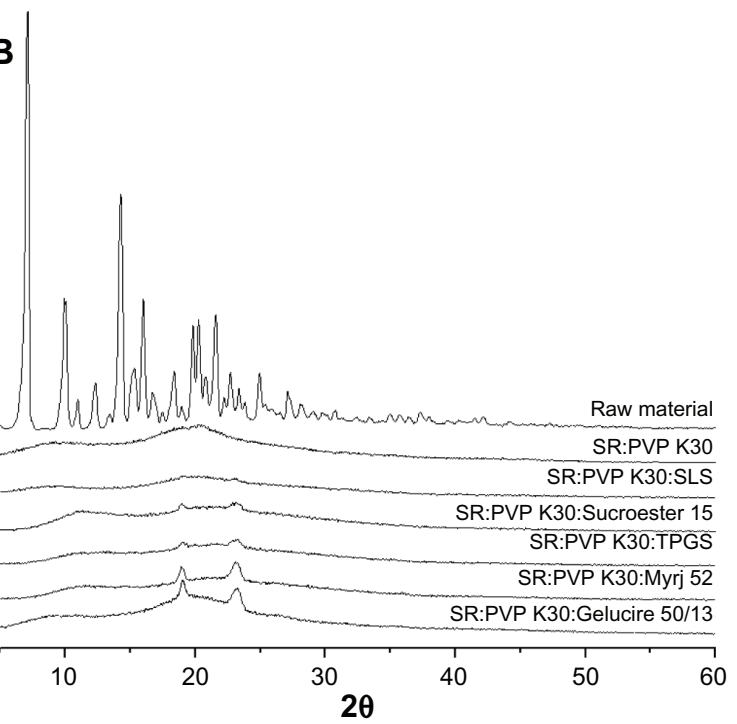

Figure 4 Differential scanning calorimetry thermograms $(\mathbf{A})$ and $\mathrm{X}$-ray diffraction patterns $(\mathbf{B})$ of raw material and sirolimus solid dispersion nanoparticles prepared by supercritical antisolvent process.

Abbreviations: SR, sirolimus; PVP, polyvinylpyrrolidone; TPGS, d- $\alpha$-tocopheryl polyethylene glycol I000 succinate; SLS, sodium lauryl sulfate.

without surfactants because of the higher supersaturation concentration over a longer time. The higher supersaturation causes increased flux across biological membranes, saturating P-glycoprotein-mediated efflux and cytochrome P450 3A4 metabolism, ${ }^{35-37}$ thereby increasing bioavailability of sirolimus. In particular, not only were surfactants such as SLS and Sucroester 15 good excipients for very fine spherical particles in the SAS process, but they also increased the bioavailability of sirolimus due to high supersaturation and rapid dissolution. The results suggest that the preparation of

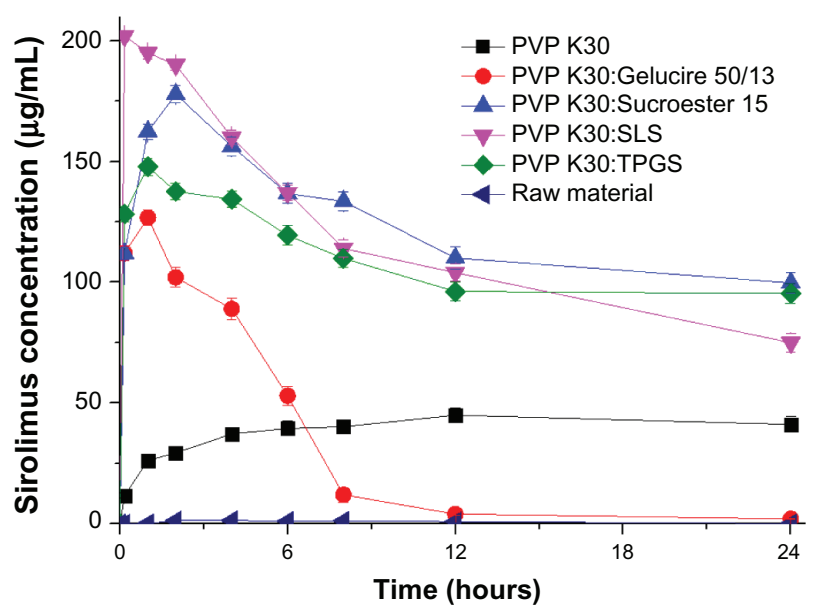

Figure $\mathbf{5}$ Kinetic solubility profiles of raw material and sirolimus solid dispersion nanoparticles prepared by the supercritical antisolvent process.

Note: Data are expressed as the mean \pm standard deviation $(n=3)$.

Abbreviations: PVP, polyvinylpyrrolidone; TPGS, d- $\alpha$-tocopheryl polyethylene glycol 1000 succinate; SLS, sodium lauryl sulfate.
PVP K30-sirolimus-surfactant nanoparticles using the SAS process may be a promising approach for improving the bioavailability of sirolimus.

\section{Photostability test}

Time-dependent changes in sirolimus content under ultraviolet irradiation were monitored to evaluate whether solid dispersion nanoparticles contribute to protecting sirolimus from photodegradation. Although $38.5 \%$ and $25.9 \%$ of sirolimus was degraded in raw material and PVP K30-sirolimus

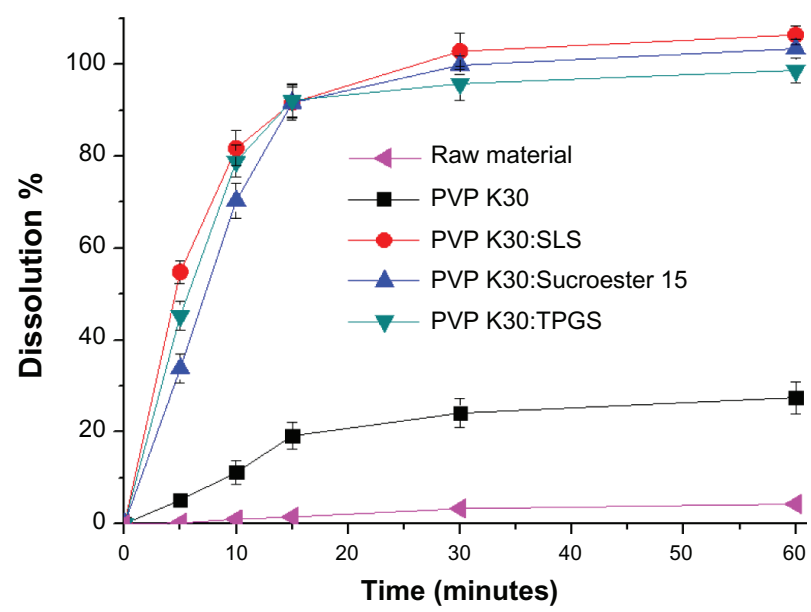

Figure 6 Powder dissolution profiles of raw material and sirolimus solid dispersion nanoparticles prepared by the supercritical antisolvent process.

Note: Data are expressed as the mean \pm standard deviation $(n=3)$.

Abbreviations: PVP, polyvinylpyrrolidone; TPGS, $d-\alpha$-tocopheryl polyethylene glycol 1000 succinate; SLS, sodium lauryl sulfate. 


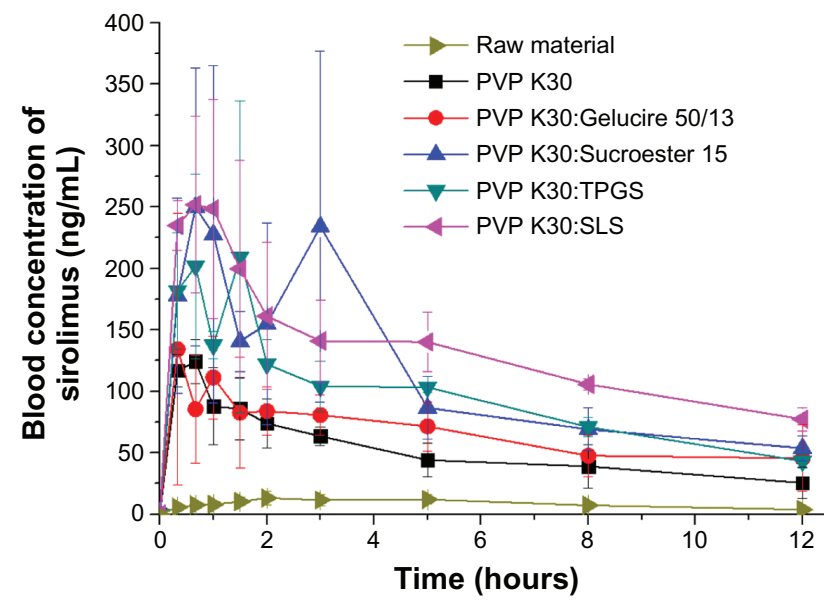

Figure 7 Blood concentration-time profile of sirolimus in rats after oral administration of raw material or sirolimus solid dispersion nanoparticles prepared by the supercritical antisolvent process at a dose equivalent to $10 \mathrm{mg}$ of sirolimus/ $\mathrm{kg}$ of body weight.

Note: Data are expressed as the mean \pm standard deviation $(n=4)$.

Abbreviations: PVP, polyvinylpyrrolidone; TPGS, d- $\alpha$-tocopheryl polyethylene glycol 1000 succinate; SLS, sodium lauryl sulfate.

nanoparticles, respectively, after 48 hours of ultraviolet irradiation, only $52.3 \%$ and $43.5 \%$ was degraded in PVP K30Sucroester 15 and PVP K30-TPGS nanoparticles, respectively (Figure 8), demonstrating stabilization of sirolimus. The degradation rates of sirolimus were $0.021,0.028,0.019$, and 0.016 per hour for sirolimus raw powder, PVP K30sirolimus nanoparticles, PVP K30-Sucroester 15-sirolimus nanoparticles, and PVP K30-TPGS-sirolimus nanoparticles, respectively.

\section{Stability test}

The stability of sirolimus was examined by periodic evaluation of the powder dissolution in water and the X-ray diffraction patterns of PVP K30-sirolimus nanoparticles, PVP K30-Sucroester 15-sirolimus nanoparticles, and PVP K30-TPGS-sirolimus nanoparticles stored at $25^{\circ} \mathrm{C} \pm 2{ }^{\circ} \mathrm{C}$

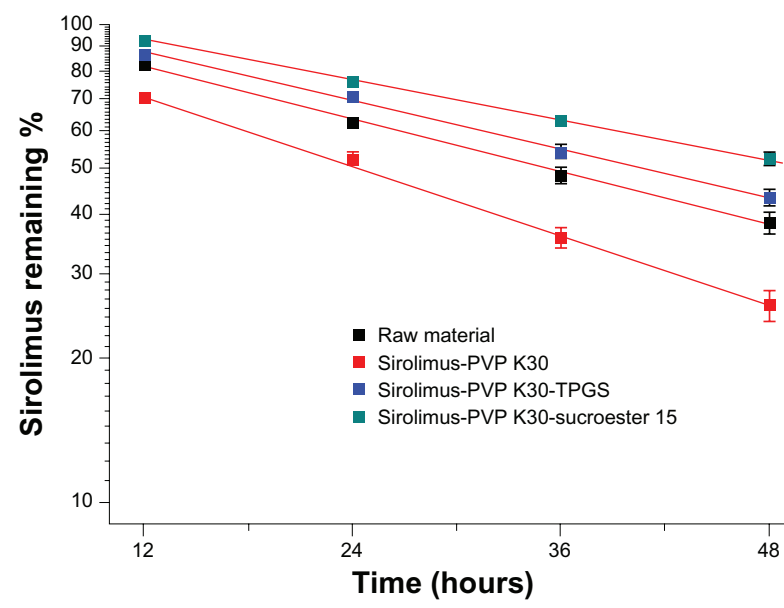

Figure 8 Photodegradation curves of raw material and sirolimus solid dispersion nanoparticles prepared by the supercritical antisolvent process. The samples were exposed to ultraviolet irradiation for $0-48$ hours at $25^{\circ} \mathrm{C} \pm 2{ }^{\circ} \mathrm{C}$ and $60 \% \pm 5 \%$ relative humidity.

Note: Data are expressed as the mean \pm standard deviation $(n=2-3)$.

Abbreviations: PVP, polyvinylpyrrolidone; TPGS, $d$ - $\alpha$-tocopheryl polyethylene glycol 1000 succinate.

and $60 \% \pm 5 \%$ relative humidity. As shown in Figure 9, the maximum dissolution percentages of sirolimus from PVP K30-sirolimus nanoparticles, PVP K30-Sucroester 15-sirolimus nanoparticles, and PVP K30-TPGS-sirolimus nanoparticles appeared to be about 25\%,100\%, and $100 \%$, and these levels were maintained during 3 months of storage. Furthermore, the X-ray diffraction patterns of solid dispersion nanoparticles were similar on day 0 and after 3 months (Figure 9). These results indicate that the amorphous state of sirolimus in solid dispersion nanoparticles remained almost unchanged for 3 months. Considering that PVP K30 inhibits recrystallization ${ }^{38}$ and Sucroester 15 and TPGS have excellent drug solubilization capacity, the combined use of PVP K30 and Sucroester 15 or TPGS may help to maintain the stability of solid dispersion nanoparticles.

Table 4 Pharmacokinetic parameters of sirolimus in rats after oral administration of raw material or solid dispersion nanoparticles

\begin{tabular}{llcll}
\hline Formulation & \multicolumn{2}{l}{ Pharmacokinetic parameter } & & \\
\cline { 2 - 5 } & $\mathbf{C}_{\max }(\mathbf{n g} / \mathbf{m L})$ & AUC $_{0 \rightarrow 12 \mathrm{~h}}$ (ng.hour/mL) & $\mathbf{T}_{\max }$ (hours) & MRT (hours) \\
\hline Raw material & $15.9 \pm 4.4$ & $101.3 \pm 14.4$ & $3.8 \pm 1.5$ & $5.11 \pm 0.51$ \\
PVP K30 & $129.8 \pm 13.9^{\mathrm{a}}$ & $601.7 \pm 121.2^{\mathrm{a}}$ & $1.0 \pm 0.4^{\mathrm{a}}$ & $4.51 \pm 0.62$ \\
PVP K30:SLS & $291.0 \pm 74.2^{\mathrm{a}, \mathrm{b}}$ & $1542.8 \pm 251.5^{\mathrm{a}-\mathrm{c}}$ & $0.7 \pm 0.3^{\mathrm{a}}$ & $4.97 \pm 0.23$ \\
PVP K30:TPGS & $247.5 \pm 98.3^{\mathrm{a}}$ & $1116.9 \pm 114.3^{\mathrm{a}} \mathrm{b}$ & $1.3 \pm 0.4^{\mathrm{a}}$ & $4.66 \pm 0.32$ \\
PVP K30:Sucroester 15 & $272.4 \pm 127.7^{\mathrm{a}, \mathrm{b}}$ & $1309.3 \pm 478.6^{\mathrm{a}-\mathrm{c}}$ & $1.8 \pm 1.3^{\mathrm{a}}$ & $4.46 \pm 0.47$ \\
PVP K30:Gelucire 50/13 & $175.9 \pm 84.3^{\mathrm{a}}$ & $771.3 \pm 162.0^{\mathrm{a}}$ & $0.8 \pm 0.3^{\mathrm{a}}$ & $4.94 \pm 0.78$ \\
\hline
\end{tabular}

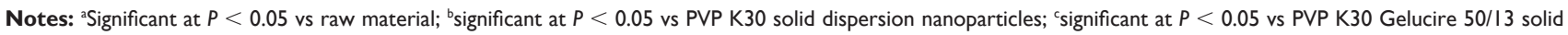
dispersion nanoparticles. Data are expressed as the mean \pm standard deviation $(n=4)$.

Abbreviations: PVP, polyvinylpyrrolidone; TPGS, d- $\alpha$-tocopheryl polyethylene glycol 1000 succinate; $M R T$, mean residence time; $C_{\text {max }}$, peak plasma concentration; $T_{\text {max }}$, time to peak concentration; AUC, area under the concentration-time curve. 


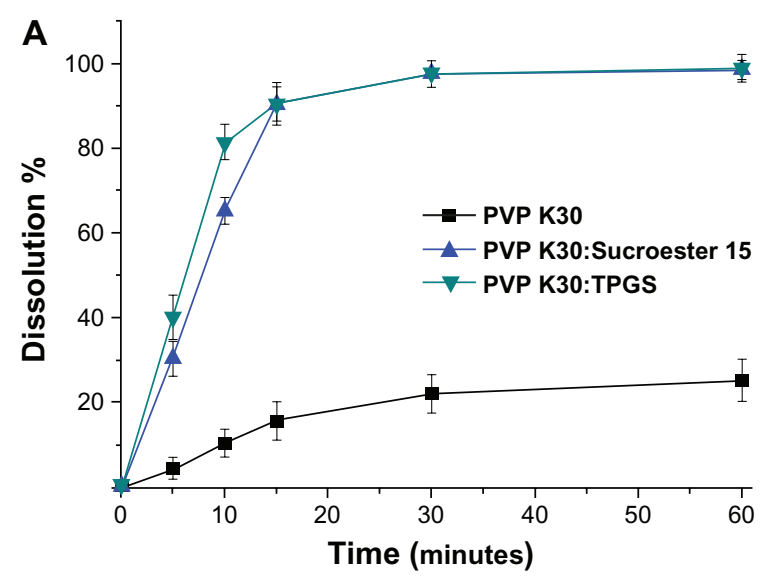

B

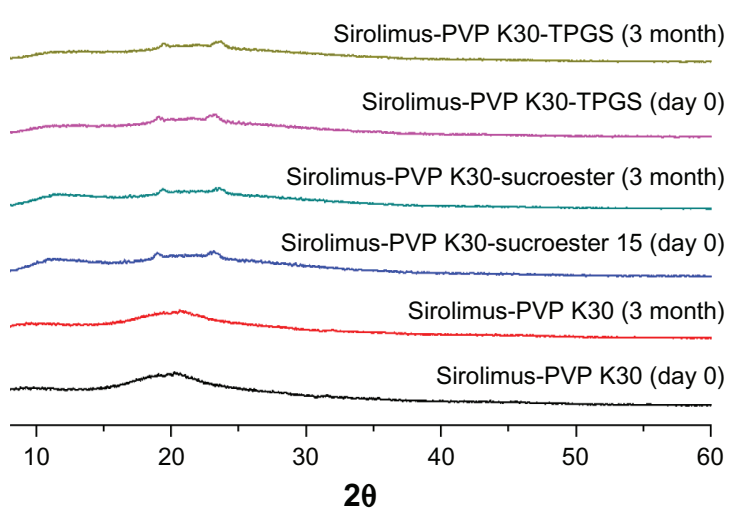

Figure 9 Powder dissolution (A) and X-ray diffraction patterns $(\mathbf{B})$ of sirolimus solid dispersion nanoparticles prepared by the supercritical antisolvent process at day 0 and after 3 months at $25^{\circ} \mathrm{C} \pm 2{ }^{\circ} \mathrm{C}$ and $60 \% \pm 5 \%$ relative humidity.

Note: Data are expressed as the mean \pm standard deviation $(n=3)$.

Abbreviations: PVP, polyvinylpyrrolidone; TPGS, d- $\alpha$-tocopheryl polyethylene glycol 1000 succinate.

\section{Conclusion}

To improve the oral absorption of sirolimus, a novel sirolimus solid dispersion nanoparticle was designed using the SAS process. PVP K30-TPGS and PVP K30-Sucroester 15 solid dispersion nanoparticles appeared to enhance the supersaturation, dissolution, and stability of sirolimus effectively. Furthermore, pharmacokinetic studies in rats indicated that solid dispersion nanoparticles significantly improved the oral absorption of sirolimus. Overall, the results indicate that PVP K30-TPGS-sirolimus and PVP K30-Sucroester 15-sirolimus solid dispersion nanoparticles demonstrate great potential for clinical application.

\section{Acknowledgments}

This work was supported by the Priority Research Centers Program through the National Research Foundation of Korea funded by the Ministry of Education, Science and Technology (2009-0093815) and, in part, by a grant from the Korea Healthcare Technology R\&D Project, Ministry for Health, Welfare and Family Affairs, Republic of Korea (A080470).

\section{Disclosure}

The authors report no conflicts of interest in this work.

\section{References}

1. Vézina C, Kudelski A, Sehgal SN. Rapamycin (AY-22,989), a new antifungal antibiotic. I. Taxonomy of the producing streptomycete and isolation of the active principle. J Antibiot (Tokyo). 1975;28:721-726.

2. Sehgal SN. Rapamune (RAPA, rapamycin, sirolimus): mechanism of action immunosuppressive effect results from blockade of signal transduction and inhibition of cell cycle progression. Clin Biochem. 1998;31:335-340.

3. Simamora P, Alvarez JM, Yalkowsky SH. Solubilization of rapamycin. Int J Pharm. 2001;213:25-29.
4. Rouf MA, Bilensoy E, Vural İ, Hincal AA. Determination of stability of rapamycin following exposure to different conditions. Euro J Pharm Sci. 2007;32(1 Suppl 1):S46.

5. Rouf MA, Bilensoy E, Vural İ, Hincal AA. Inclusion complexation of rapamycin with beta-cyclodextrin to improve solubility and stability of the drug. The 2nd BBBB Conference on Pharmaceutical Sciences, September 13-15, 2007, Tallinn-Tartu, Estonia.

6. Buech G, Bertelmann E, Pleyer U, Siebenbrodt I, Borchert HH. Formulation of sirolimus eye drops and corneal permeation studies. J Ocul Pharmacol Ther. 2007;23:292-303.

7. Alemdar AY, Sadle D, McAlister VC, Mendez I. Liposomal formulations of tacrolimus and rapamycin increase graft survival and fiber outgrowth of dopaminergic grafts. Cell Transplant. 2004;13:263-271.

8. Rosen H, Abribat T. The rise and rise of drug delivery. Nat Rev Drug Discov. 2005;4:381-385.

9. Junghanns JU, Muller RH. Nanocrystal technology, drug delivery and clinical applications. Int J Nanomed. 2008;3:295-310.

10. Preetham AC, Satish CS. Formulation of a poorly water-soluble drug sirolimus in solid dispersions to improve dissolution. J Disp Sci Technol. 2011;32:778-783.

11. Vasconcelos T, Sarmento B, Costa P. Solid dispersions as strategy to improve oral bioavailability of poor water soluble drugs. Drug Discov Today. 2007;12:1068-1075.

12. Leuner C, Dressman J. Improving drug solubility for oral delivery using solid dispersions. Euro J Pharm Biopharm. 2000;50:47-60.

13. Srinarong P, de Waard H, Frijlink HW, Hinrichs WLJ. Improved dissolution behavior of lipophilic drugs by solid dispersions: the production process as starting point for formulation considerations. Expert Opin Drug Deliv. 2011;8:1121-1140.

14. Serajuddin ATM. Solid dispersion of poorly water-soluble drugs: early promises, subsequent problems, and recent breakthroughs. J Pharm Sci. 1999;88:1058-1066.

15. Janssens S, Van den Mooter G. Review: physical chemistry of solid dispersions. J Pharm Pharmacol. 2009;61:1571-1586.

16. Craig DQ. The mechanisms of drug release from solid dispersions in water-soluble polymers. Int J Pharm. 2002;231:131-144.

17. Karavas E, Georgarakis E, Sigalas MP, Avgoustakis K, Bikiaris D. Investigation of the release mechanism of a sparingly water-soluble drug from solid dispersions in hydrophilic carriers based on physical state of drug, particle size distribution and drug-polymer interactions. Euro J Pharm Biopharm. 2007;66:334-347.

18. Won DH, Kim MS, Lee S, Park JS, Hwang SJ. Improved physicochemical characteristics of felodipine solid dispersion particles by supercritical anti-solvent precipitation process. Int J Pharm. 2005;301:199-208. 
19. Jun SW, Kim MS, Jo GH, et al. Cefuroxime axetil solid dispersions prepared using solution enhanced dispersion by supercritical fluids. J Pharm Pharmacol. 2005;57:1529-1537.

20. Jun SW, Kim MS, Kim JS, et al. Preparation and characterization of simvastatin/hydroxypropyl-beta-cyclodextrin inclusion complex using supercritical antisolvent (SAS) process. Eur J Pharm Biopharm. 2007;66: 413-421.

21. Kalani M, Yunus R. Application of supercritical antisolvent method in drug encapsulation: a review. Int J Nanomed. 2011;6:1429-1442.

22. Fages J, Lochard H, Letourneau JJ, Sauceau M, Rodier E. Particle generation for pharmaceutical applications using supercritical fluid technology. Powder Technol. 2004;141:219-226.

23. Pasquali I, Bettini R, Giordano F. Solid-state chemistry and particle engineering with supercritical fluids in pharmaceutics. Euro J Pharm Sci. 2006;27:299-310.

24. Ricciutelli M, Di Martino P, Barboni L, Martelli S. Evaluation of rapamycin chemical stability in volatile-organic solvents by HPLC. J Pharm Biomed Anal. 2006;41:1070-1074.

25. Wang X, Venkatraman SS, Boey FY, Loo JSC, Tan LP. Controlled release of sirolimus from a multilayered PLGA stent matrix. Biomaterials. 2006;27: 5588-5595.

26. Paine MF, Leung LY, Lim HK, et al. Identification of a novel route of extraction of sirolimus in human small intestine: roles of metabolism and secretion. J Pharmacol Exp Ther. 2002;301:174-186.

27. Kim MS, Jin SJ, Kim JS, et al. Preparation, characterization and in vivo evaluation of amorphous atorvastatin calcium nanoparticles using supercritical antisolvent (SAS) process. Eur J Pharm Biopharm. 2008;69: 454-465.

28. Streit F, Christians U, Schiebel UM, Meyer A, Sewing KF. Structural identification of three metabolites and a degradation product of the macrolide immunosuppressant sirolimus (rapamycin) by electrosprayMS/MS after incubation with human liver microsomes. Drug Metab Dispos. 1996;24:1272-1278.
29. Maleki S, Graves S, Becker S, et al. Therapeutic monitoring of sirolimus in human whole-blood samples by high-performance liquid chromatography. Clin Ther. 2000;22 Suppl B:B25-B27.

30. Wacher VJ, Silverman JA, Wong S, et al. Sirolimus oral absorption in rats is increased by ketoconazole but is not affected by D-alphatocopheryl poly(ethylene glycol 1000) succinate. J Pharmacol Exp Ther. 2002;303:308-313.

31. Juppo AM, Boissier C, Khoo C. Evaluation of solid dispersion particles prepared with SEDS. Int J Pharm. 2003;250:385-401.

32. Kim MS, Kim JS, Hwang SJ. Enhancement of wettability and dissolution properties of cilostazol using the supercritical antisolvent process: effect of various additives. Chem Pharm Bull. 2010;58:230-233.

33. Alonzo DE, Gao Y, Zhou D, Mo H, Zhang GGZ, Taylor LS. Dissolution and precipitation behavior of amorphous solid dispersions. J Pharm Sci. 2011;100:3316-3331.

34. Konno H, Handa T, Alonzo DE, Taylor LS. Effect of polymer type on the dissolution profile of amorphous solid dispersions containing felodipine. Eur J Pharm Biopharm. 2008;70:493-499.

35. Lampen A, Zhang Y, Hackbarth I, Benet LZ, Sewing KF, Christians U. Metabolism and transport of the macrolide immunosuppressant sirolimus in the small intestine. J Pharmacol Exp Ther. 1998;285:1104-1112.

36. Paine MF, Leung LY, Watkins PB. New insights into drug absorption: studies with sirolimus. Ther Drug Monit. 2004;26:463-467.

37. Cummins CL, Jacobsen W, Christians U, Benet LZ. CYP3A4-transfected Caco-2 cells as a tool for understanding biochemical absorption barriers: studies with sirolimus and midazolam. J Pharmacol Exp Ther. 2004;308: $143-155$.

38. Abu-Diak OA, Jones DS, Andrews GP. An investigation into the dissolution properties of celecoxib melt extrudates: understanding the role of polymer type and concentration in stabilizing supersaturated drug concentrations. Mol Pharm. 2011;8:1362-1371.
International Journal of Nanomedicine

\section{Publish your work in this journal}

The International Journal of Nanomedicine is an international, peerreviewed journal focusing on the application of nanotechnology in diagnostics, therapeutics, and drug delivery systems throughout the biomedical field. This journal is indexed on PubMed Central,

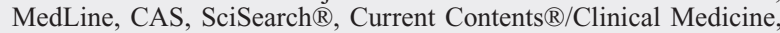

\section{Dovepress}

Journal Citation Reports/Science Edition, EMBase, Scopus and the Elsevier Bibliographic databases. The manuscript management system is completely online and includes a very quick and fair peer-review system, which is all easy to use. Visit http://www.dovepress.com/ testimonials.php to read real quotes from published authors 